\title{
Midterm outcomes of transmyocardial laser revascularization with intramyocardial injection of adipose derived stromal cells for severe refractory angina
}

\author{
Janusz Konstanty-Kalandyk ${ }^{1}$, Krzysztof Bartuś ${ }^{1}$, Jacek Piątek ${ }^{1}$, Venkat Vuddanda ${ }^{2}$, Randall Lee ${ }^{3}$, \\ Anna Kędziora ${ }^{1}$, Jerzy Sadowski ${ }^{1}$, Dhanunjaya Lakkireddy ${ }^{4}$, Bogusław Kapelak ${ }^{1}$ \\ ${ }^{1}$ Department of Cardiovascular Surgery and Transplantology, Jagiellonian University, John Paul II Hospital, Krakow, Poland \\ ${ }^{2}$ Warren Alpert School of Medicine, Brown University, Miriam Hospital, Providence, Harvard Medical School, Boston, USA \\ ${ }^{3}$ Division of Cardiac Electrophysiology, Cardiovascular Research Institute, Institute for Regenerative Medicine, University of California, \\ San Francisco, USA \\ ${ }^{4}$ Cardiovascular Research Institute, University of Kansas, Kansas City, USA
}

Adv Interv Cardiol 2018; 14, 2 (52): 176-182

DOI: https://doi.org/10.5114/aic.2018.76409

\begin{abstract}
A bstract
Introduction: Refractory angina has limited effective therapeutic options and often contributes to frequent hospitalizations, morbidity and impaired quality of life.

Aim: We sought to examine midterm results of a bio-interventional therapy combining transmyocardial laser revascularization (TMLR) and intramyocardial injection of adipose derived stem cells (ADSC) in patients with refractory angina not amenable to percutaneous or surgical revascularization.

Material and methods: We included 15 patients with severe refractory angina and anterior wall ischemia who were ineligible for revascularization strategies. Adipose tissue was harvested and purified, giving the stem cell concentrate. All patients underwent left anterior thoracotomy and TMLR using a low-powered holmium : yttrium-aluminum-garnet laser and intramyocardial injection of ADSC using a combined delivery system.

Results: No deaths or major adverse cardiovascular or cerebrovascular events were observed in the 6-month follow-up. Mean ejection fraction increased from 35\% to 38\%, and mean Canadian Cardiovascular Society Angina Score decreased from 3.2 to 1.4, with decreased necessity of nitrate usage. Seventy-three percent of patients reported health improvement particularly regarding general health and bodily pain. Improvement in endocardial movement, myocardial thickening and stroke volume index (35.26 to $46.23 \mathrm{ml} / \mathrm{m}^{2}$ ) on cardiac magnetic resonance imaging (MRI) was observed in 3 patients who had repeat CMR imaging after 6 months.

Conclusions: Our study suggested that interventional therapy combining TMLR with intramyocardial implantation of ADSC may reduce symptoms and improve quality of life in patients with refractory angina. These early findings need further validation in large scale randomized controlled trials.
\end{abstract}

Key words: ischemic heart disease, adipose-derived stromal cells, myocardial function, refractory angina.

\section{Introduction}

Ischemic heart disease (IHD) is the leading cause of death worldwide [1]. Advances in revascularization strategies have led to improved survival after acute myocardial infarction and resulted in more patients living with the disabling symptoms of chronic stable angina (refractory angina) and ischemic heart failure [2]. These latter populations represent a highly symptomatic and health care resource intensive group of patients.
Refractory angina is not unstable angina or myocardial infarction but is stable angina that is not eliminated by current optimal medical therapy and/or revascularization. Also, it is not uncommon to find patients with significant residual angina after revascularization [3].

Although it is difficult to define simple criteria for medically refractory ischemia that apply to diverse populations, it is clear that there are patients for whom medical therapy fails to control their symptoms [4].

\section{Corresponding author:}

Janusz Konstanty-Kalandyk MD, Department of Cardiovascular Surgery and Transplantology, Jagiellonian University, John Paul II Hospital, 80 Prądnicka St, 31-202 Krakow, Poland, phone: +48 505038 254, e-mail: jakonstanty@poczta.onet.pl

Received: 7.05.2018, accepted: 14.05.2018. 
The majority of them have exhausted their options of medical and standard revascularization therapies (percutaneous coronary intervention, bypass graft) and are in need of alternative therapeutic strategies $[5,6]$ mainly due to limitation of quality of life.

It has been estimated that at least 300000 patients in the United States experience refractory angina pectoris, and that this number could be as high as 900 000, with 25 000-75 000 new cases diagnosed annually [7].

Transmyocardial laser revascularization (TMLR) and cell therapies using adult stem cells have emerged as experimental treatment modalities for patients with refractory angina who are not amenable to percutaneous or surgical revascularization. There is cumulative evidence suggesting that these therapies result in improvement of angina stage, exercise capacity, and quality of life [8-11]. Among several mechanisms proposed, evidence supports angiogenesis within the treated myocardium as a major contributing factor for symptom improvement with the above-mentioned therapies [12].

Mesenchymal stem cells (MSCs) along with other pluripotent stem cells have been said to be an effective tool for angiogenesis, cardiac regeneration and hence cardiac tissue recovery.

Mesenchymal stem cells are present in almost all tissues of the body and are mainly located in the perivascular alcove. They can be derived from disparate adult (e.g. peripheral blood, adipose tissue, bone marrow) and neonatal (umbilical cord, amnion, cord blood and placenta) tissues, based on their therapeutic application [13].

Bone marrow derived mesenchymal stem cells (BM-MSCs) are the most commonly used adult stem cells because of their wide availability and multipotency, i.e. ability to differentiate into cells of mesenchymal origin (osteoblasts, cardiomyocytes) [14]. However, BM-MSCs are suboptimal because of the invasive procedure required for harvesting and decline in proliferation and differentiation potential of cells with increasing senescence [15]. As an alternative, Zuk et al. [16] introduced a multipotent, stem cell population isolated from adipose tissue that is phenotypically similar to the BM-MSCs. Adipose tissue is composed of mature adipocytes and a supportive stromal vascular fraction (SVF). Stromal vascular fraction is a heterogeneous mixture of cells including multipotent adipose tissue derived stem cells (ADSC). The ease of repeated harvesting by a minimally invasive method (liposuction), quality of the harvested cells, proliferation capacity of the stem cells that does not decline with the age of the patient, and the angiogenic potential in the IHD population [17-20], make ADSC the preferred alternative cell source for cellular regenerative therapies [21-23].

Combining TMLR with cell therapy resulted in an increase in vascular density as compared to TMLR alone [24-26]. Therefore bio-interventional therapy, i.e. a combination of TMLR and intramyocardial injection of adult stem cells, is being treated as the "holy grail" of myocardial remodeling and is believed to combine the advantages of both laser and cell therapy for improvement of symptoms and cardiac function [27].

\section{Aim}

The aim of the study was to present 6-month follow-up clinical results of this combined therapy using ADSC.

\section{Material and methods}

\section{Patient selection}

The study population included 15 patients with severe refractory angina due to anterior wall myocardial ischemia who were ineligible for revascularization strategies ( $\mathrm{PCl}$ and bypass graft).

Refractory angina was defined as stable angina pectoris, presence of coronary artery disease, in patients who despite optimal medical therapy (OMT) have severe angina and functional class III or IV according to the Canadian Cardiovascular Society (CCS). Optimal medical therapy included maximum tolerated doses of at least two anti-ischemic agents ( $\beta$-blockers, calcium channel blockers, and long acting nitrates), antiplatelet therapy, and aggressive lipid and blood pressure lowering therapies.

Anterior wall myocardial ischemia was defined as impairment of flow in the left anterior descending (LAD) artery (> 75\% stenosis) confirmed by coronary angiography, cardiac magnetic resonance (CMR) imaging demonstrating hypokinesis/akinesis of the anterior wall and non-transmural $(<25 \%)$ anterior wall scar. A heart team comprising three cardiovascular surgeons and two cardiologists determined the ineligibility for percutaneous or surgical revascularization based on coronary angiography.

Exclusion criteria were left ventricle ejection fraction (LVEF) of less than 20\%, acute myocardial infarction within 6 months before enrollment, history of malignancy, renal dysfunction (glomerular filtration rate $<30 \mathrm{ml}$ $\mathrm{min} / 1.73 \mathrm{~m}^{2}$ ), unexplained hematological abnormalities, valvular heart disease requiring surgery, congenital heart disease, malignant arrhythmias, contraindications for general anesthesia and inability to undergo CMR imaging (for example: claustrophobia, allergy to contrast).

Of the 75 patients ( 60 men $-80 \%, 15$ women - 20\%) screened, 15 patients (12 men and 3 woman) were included in the study. Other patients could not be included in the study because they: met the exclusion criteria, had a pacemaker, were admitted for percutaneous coronary interventions $(\mathrm{PCl})$ or coronary artery bypass grafting (CABG), or did not consent to the study.

Quality of life was assessed on the basis of Medical Outcomes Questionnaire Short Form 36 Health Survey (SF-36). The SF-36 measures eight scales: physical functioning (PF), role physical (RP), bodily pain (BP), general health $(\mathrm{GH})$, vitality $(\mathrm{VT})$, social functioning (SF), role 
emotional (RE), and mental health $(\mathrm{MH})$. All items are scored so that a high score defines a more favorable health state. In addition, each item is scored on a 0 to 100 range so that the lowest and highest possible scores are 0 and 100, respectively. Scores represent the percentage of the total possible score achieved.

The institutional review board ethics committee approved the protocol and written informed consent was obtained from each patient.

\section{Cell preparation and delivery}

Subcutaneous adipose tissue was successfully harvested from all patients through elective cosmetic liposuction. The amount of harvested tissue depended on the patient's anatomy. The Celution 800/CRS System (Cytori Therapeutics, San Diego, CA) was used to obtain ADSC according to the manufacturer's instructions; it has an average viable cell yield of $2-5 \times 10^{5}$ cells/g. The Celution system is an automated system, which prepares ADSCs by washing, enzymatic digestion of tissue and concentration after fat harvest in a self-contained system. This dedicated medical equipment enabled reliable and reproducible isolation of adipose-derived stromal cells from fat tissue [28].

A mean volume of 240 (range: $120-360) \mathrm{ml}$ of adipose tissue and an average of $40 \times 10^{6}$ (range: $37 \times 10^{6}$ to $65 \times 10^{6}$ ) ADSC with a mean cell viability of $80.6 \pm 5.1 \%$ were harvested from each patient.

The harvested suspension of stem cells was then immediately delivered to the patient from whom it was obtained, without any manipulation. Each patient had five channels created with simultaneous delivery of $1 \mathrm{ml}$ of suspension around each channel during TMLR and implantation of ADSC.

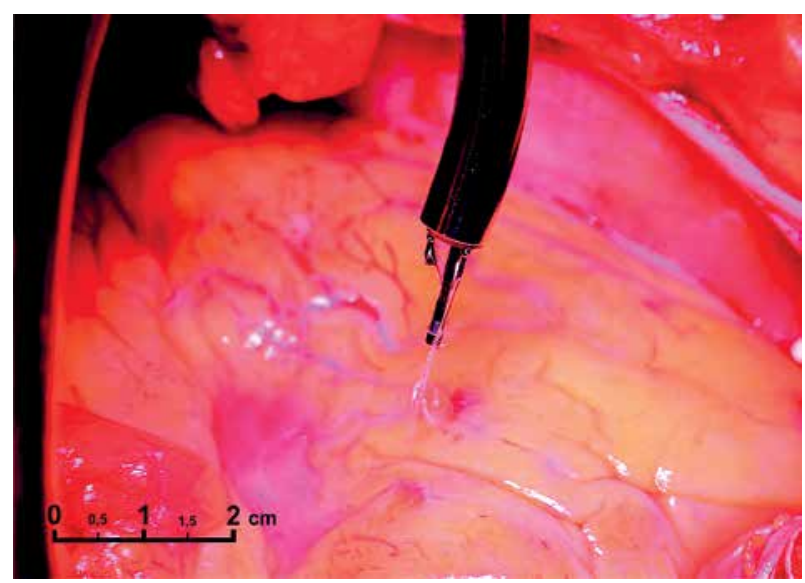

Figure 1. Transmyocardial laser revascularization combined with stem cell delivery being performed with the PHOENIX combined delivery system (Cardiogenesis, Irvine CA, U.S.A.). Hand piece consists of a flexible, fiber optic scope, with 3 needles, for delivering stem cells into the myocardium around the channel produced by the laser
All patients underwent left anterior thoracotomy and TMLR using a low powered (7 W) holmium : yttrium-aluminum-garnet (Ho:YAG) laser and intramyocardial injection of ADSC was performed using the PHOENIX combined delivery system (Cardiogenesis, Irvine CA, U.S.A.) (Figure 1). Both the treatments were performed under general anesthesia using intravenous infusion of propofol, sufentanil, and pancuronium. Cardiac rhythm, central venous pressure, and arterial blood gas were monitored during the procedure.

\section{Six-month follow-up study outcomes}

Safety was assessed by recording the occurrence of malignant arrhythmias, major adverse cardiovascular or cerebrovascular events (MACCE), defined as cardiac death, myocardial infarction, stroke, emergent percutaneous or surgical revascularization, or any other adverse events from enrollment to the 6-month follow-up.

Efficacy was evaluated by the number of hospitalizations for angina. Angina severity was assessed by sublingual nitroglycerine (NTG) use and CCS angina class at the 6-month follow-up. Health status was evaluated on the basis of the Study Health Survey Questionnaire (SF-36).

To further evaluate the cardiac function, left ventricular ejection fraction (LVEF) assessment was performed using two-dimensional transthoracic echocardiography (2D-TTE) at baseline and at 6-month follow-up. Cardiac magnetic resonance imaging was performed after the TMLR procedure, using a 1.5-Tesla whole body scanner (Magnetom Sonata Maestro Class, Erlangen, Germany) to assess changes in the myocardium.

\section{Statistical analysis}

This is the first study in humans looking at the feasibility and safety of combining TMLR and intramyocardial injection of ADSC. No prior data were available for power calculations. Accordingly, the results are presented as the change from baseline in all the patients. As a phase I/Ila study, statistical assessment of efficacy is not the goal of the study. We believed that it would not be correct to display them because these were not the pre-specified aims of the study. The authors take full responsibility for the integrity of the data. All authors have read and agree to the manuscript as written.

\section{Results}

Fifteen patients -12 male and 3 female, with a mean age of 65 years (ranging from 55 to 74 years) - were enrolled at our institution from September 2015 to April 2016. Nine patients had chronic total occlusion of the LAD while the other 6 had severe (75\% to $99 \%$ ) stenosis of the LAD with median CCS angina class of III. The baseline characteristics of the patients including all the comorbidities are shown in Table I. 
No peri-procedural complications were observed. All patients were discharged on the ninth postoperative day. No malignant arrhythmias or MACCE were reported during the 6-month follow-up period (Table I).

Mean CCS angina class improved from 3.2 to 1.4 at the 6-month follow-up (Figure $2 \mathrm{~A}$ ). The necessity of nitrate usage decreased from $15 \pm 10.4$ to $1.2 \pm 3.5$ days. No patient required hospitalization for angina or other cardiovascular problems during the 6-month follow-up period.

According to the SF-36 Health questionnaire, after 6 months of observation, $73 \%$ reported a health improvement. All patients reported that they could walk 100 meters and climb 1 floor with little or no limitations. Seventy-one percent of patients after 6 months felt symptoms of angina very rarely or never.

The quality of life improved in the dimensions regarding physical functioning, bodily pain and general health (Figure 3).

There was a 3\% increase in mean LVEF on 2D-TTE at the 6-month follow-up in whole group (Figure $2 \mathrm{~B}$ ).

Three patients who underwent repeat $C M R$ at the 6-month follow-up as per the request of ethics committee demonstrated an increase in mean LVEF from $24 \%$ to $27 \%$ and stroke volume index (SVI) from 35.26 to 46.23 $\mathrm{ml} / \mathrm{m}^{2}$ (Figure 4). Cardiac magnetic resonance also revealed improvement of endocardial movement and myocardial thickening in the treated area.

\section{Discussion}

This was the first in-human study evaluating the clinical results of combining TMLR and intramyocardial injection of ADSC in patients with severe refractory angina. We were able to successfully harvest and deliver the ADSC in high numbers, in real time ( $2 \mathrm{~h})$ and combine it with TMLR with no peri-procedural complications. No one sustained MACCE, malignant arrhythmias, or any other adverse events during the follow-up period. The effect sizes noted in our study are low, and it will be important to further examine safety in future large scale clinical trials. This is especially true given the adverse events reported in the ATHENA trials [23]. Eighteen of 31 (58.1\%) patients were reported to have at least one serious adverse event during the trial (ADSC 9/17 (52.9\%), placebo $9 / 14(64.3 \%))$. The reasons for such high adverse event rates in the ATHENA trials are unclear but could be dependent on cell delivery techniques used. Our strategy reported here might offer an advantage and must be tested in further large-scale studies.

During the follow-up, there was a reduction in CCS angina class, nitrate use, hospitalization for angina, and improvement in cardiac function (LVEF). Our results are comparable to the results from previous studies such as APOLLO [29], PRECISE [30], and MyStromalCell [31], which also demonstrated the safety and feasibility of
Table I. Baseline characteristics and 6-month follow-up results $(n=15)$

\begin{tabular}{|c|c|}
\hline Parameter & Result \\
\hline Chronic ischemic heart disease & $100 \%(15)$ \\
\hline Age, mean (range) [years] & $65(55-74)$ \\
\hline BMI $\left[\mathrm{kg} / \mathrm{m}^{2}\right]$ & $29.8(24-42)$ \\
\hline BSA women & 1.7 \\
\hline BSA men & 1.93 \\
\hline Post-Ml & $80 \%(12)$ \\
\hline HA & $93 \%(14)$ \\
\hline DM & $33 \%(5)$ \\
\hline Post-PCl & $33 \%(5)$ \\
\hline Post-CABG & $20 \%(3)$ \\
\hline \multicolumn{2}{|l|}{ LAD: } \\
\hline СТО & $60 \%(9)$ \\
\hline Significant stenosis (75-99\% stenosis) & $40 \%(6)$ \\
\hline Hypercholesterolemia & $87 \%(13)$ \\
\hline Peripheral atherosclerosis & $33 \%(5)$ \\
\hline LVEF (mean) & $34.8 \%$ \\
\hline \multicolumn{2}{|l|}{ CCS: } \\
\hline 1 & - \\
\hline 2 & $13 \%(2)$ \\
\hline 3 & $60 \%(9)$ \\
\hline 4 & $27 \%(4)$ \\
\hline \multicolumn{2}{|l|}{ 6-month follow-up: } \\
\hline Death & 0 \\
\hline MACCE & 0 \\
\hline
\end{tabular}

Data shown as mean $\pm S D$ or as median (IQR), or number (percentage). BMI - body mass index, BSA - body surface area, MI - myocardial infarction, $P C l$ percutaneous coronary intervention, $C A B G$ - coronary artery bypass grafting $\angle A D$ - left anterior descending. CTO - chronic total occlusion, LVEF - left ventricle ejection fraction, MACCE - major adverse cardiovascular or cerebrovascular event, CCS - Canadian Cardiovascular Society scale.

ADSC use. In addition, the results indicate that ADSC use preserves cardiac function, improves cardiac perfusion, and even reduces scar tissue size, thereby reinforcing the findings of the previous preclinical trials.

Patients with refractory angina had reduced quality of life compared to the remaining population of patients with ischemic heart disease. Dimensions in the quality of life especially concern bodily pain and general health [32]. In our study, 6 months after combining TMLR and intramyocardial injection of ADSC in patients with severe refractory angina, quality of life improved in the dimensions regarding physical functioning, bodily pain and 
A

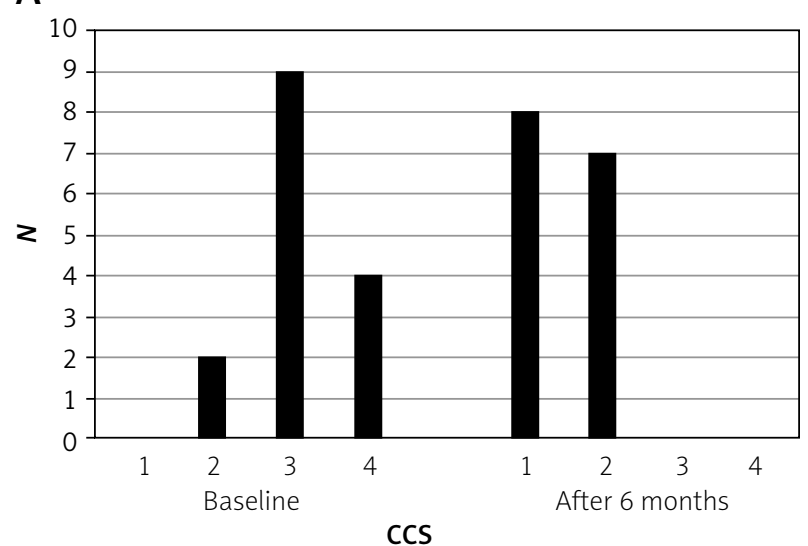

B

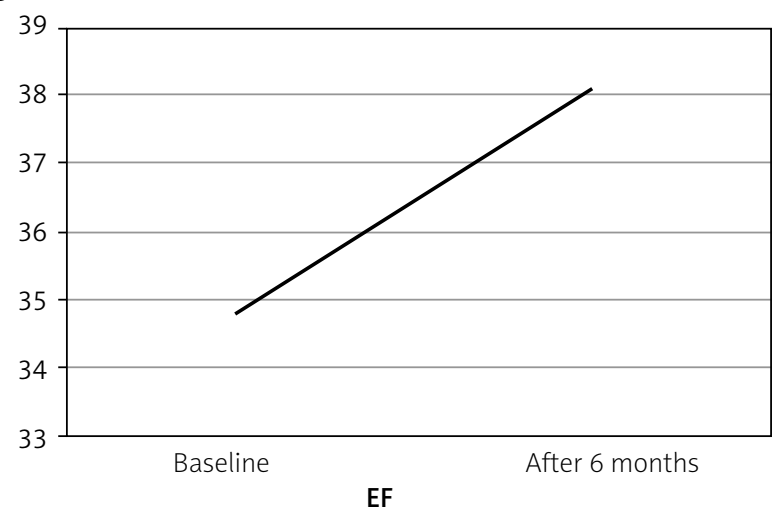

Figure 2. A - Canadian Cardiovascular Society (CCS) Scale for Angina and B - left ventricle ejection fraction (EF) (\%): at baseline compared to 6-month follow-up in study population after adipose tissue derived stem cell transplantation

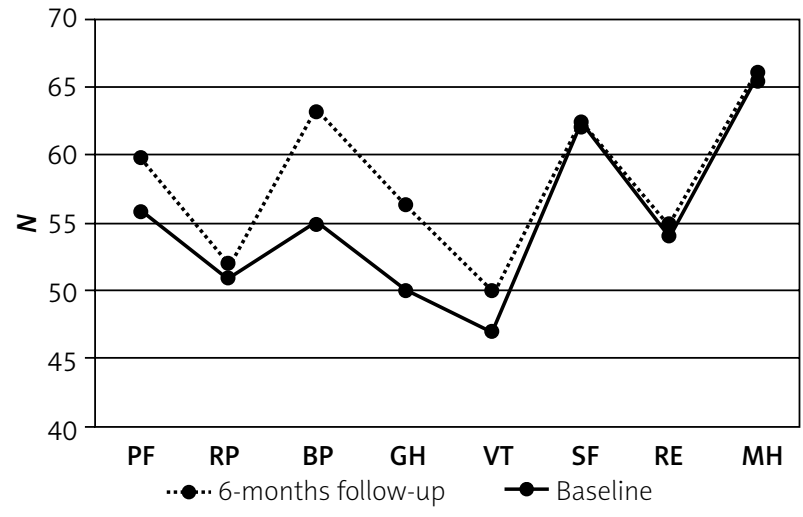

Figure 3. Changes from baseline to 6 months in domain scores for the SF-36: physical functioning $(\mathrm{PF})$, role physical $(\mathrm{RP})$, bodily pain $(\mathrm{BP})$, general health $(\mathrm{GH})$, vitality (VT), social functioning (SF), role emotional (RE), and mental health $(\mathrm{MH})$ general health. Similar benefits in terms of symptoms and quality of life (SF-36) after autologous injection of ADSC were reported in the publication from the ATHENA trial [23].

Unfortunately, no firm conclusions could be drawn from the ATHENA trial because of its early termination due to non-ADSC-related adverse events and prolonged enrollment time.

The meta-analysis published by Khan et al. also indicates that cell-based therapies are not only safe but also lead to an improvement in indices of angina, relevant clinical outcomes, and myocardial perfusion in patients with refractory angina [33]. Although the use of cell therapy in other cardiovascular conditions such as heart failure has been less successful, the data to support its use in refractory angina are evident and warrant continued studies in larger clinical trials [3].
A

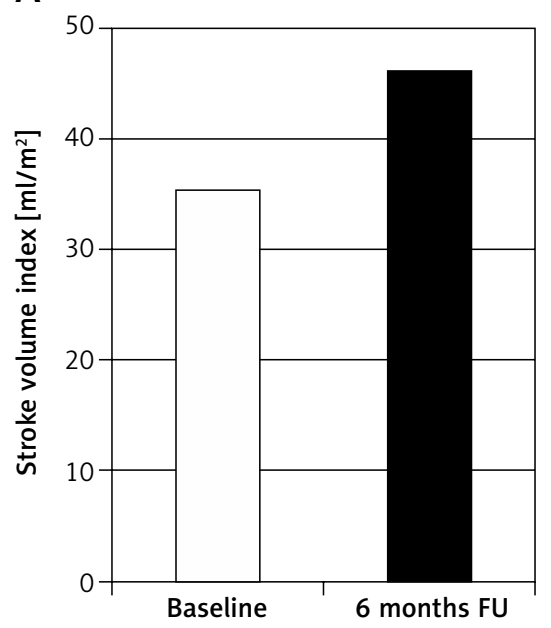

B

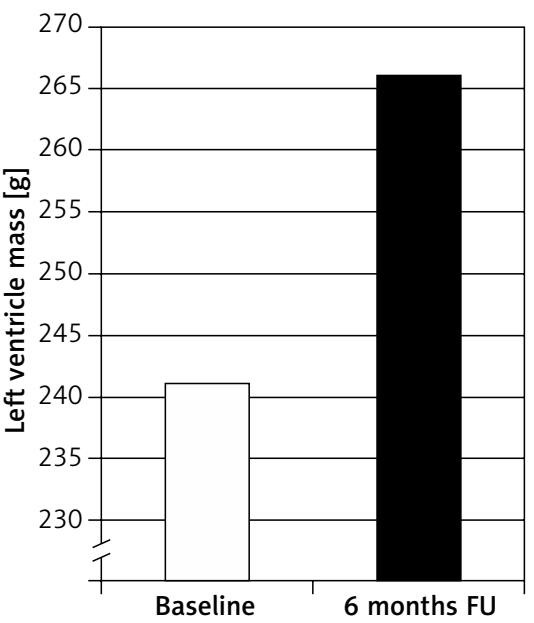

C

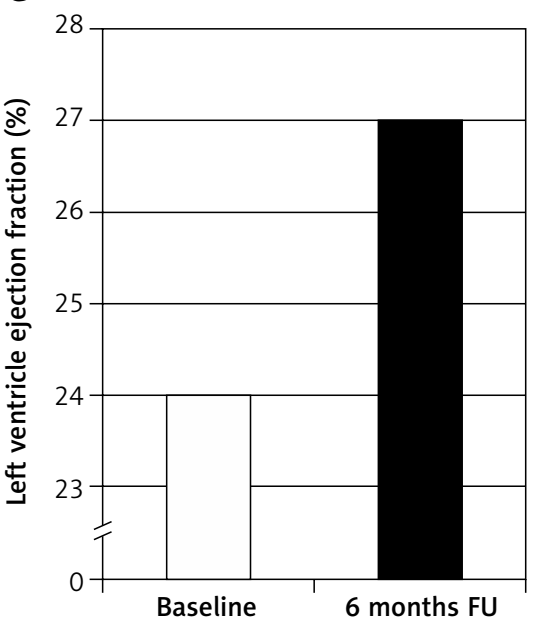

Figure 4. Improvement in cardiac MRI parameters from baseline to 6-month follow-up $(n=3)$ : $\mathbf{A}$ - stroke volume index, $\mathbf{B}$ - left ventricle mass, $\mathbf{C}$ - left ventricle ejection fraction 
We considered the ADSC production of paracrine factors and their role in myocardial regeneration or vasculogenesis. It is expected that patients with refractory angina and advanced ischemic heart disease will benefit most from neo-angiogenesis of ischemic myocardium. Analyzing the area of the myocardium in which stem cells were implanted, we assessed the endocardial movement and myocardial thickening and their impact on the parameters of left ventricle function. The improvement in the endocardial movement, inwards movement and myocardial thickening of the anterior heart wall may be the result of an improvement of blood supply and remodeling process in the study area. The observed improvement in function of the anterior heart wall directly affects the function of the entire left ventricle, which is estimated on the basis of increased stroke volume index and LVEF. Our results from CMR imaging analysis were similar to the results from previous studies performed on porcine models [34, 35]. Though improvement in left ventricle function after ADSC implantation in patients with ischemic cardiomyopathy has been well reported, the efficacy of the different cell delivery techniques is still unclear and the optimal delivery technique for a particular disease still needs to be defined. It was found that direct injection into the myocardium immediately after LAD occlusion provided the largest stem cell retention in the injured myocardium ( $14 \pm 4 \%$ of the total injected cells) [36]. Direct surgical myocardial injection can be performed in hypokinetic myocardial areas that are not suitable for surgical bypass grafting [37]. The safety of intramyocardial stem cell transplantation is well proved by many studies [26, 38, 39].

Transmyocardial laser revascularization entails the creation of laser channels within the ischemic myocardium in an effort to improve perfusion by angiogenesis. Even though TMLR is thought to induce signaling via myocardial injury and inflammation, the quantity and duration of native stem cell homing have been heavily debated.

Transmyocardial laser revascularization plus intramyocardial injection of ADSC offers the cumulative benefits of both laser and cell-based therapies and avoids the disadvantages associated with BM-MSC. Given the small sample size and lack of a sham-treated control group, the efficacy results observed in our study must be interpreted with caution.

The major limitations of the current study are the small sample size and lack of a control group, which limits the statistical rigor of our findings and questions our efficacy results. However, the improvement in symptoms was accompanied by an improvement in myocardial function. Despite these limitations, our study provides an important opportunity to explore a new therapeutic option that has a great potential to improve the quality of life. These early findings need to be further validated by large multicenter randomized controlled trials.

\section{Conclusions}

Our study demonstrates that TMLR combined with intramyocardial implantation of ADSC in patients with chronic refractory angina may be a safe and feasible option. In terms of efficacy, the improved angina class, quality of life and myocardial function noted in our study must be interpreted with caution, as without a sham-treated control group, no firm conclusions can be made about the efficacy of either ADSC or TMLR. This early experience needs future investigation and validation from large scale clinical trials.

\section{Acknowledgments}

This study was funded by the Polish national science center (contract number UMO-2011/03/B/NZ5/01437) and approved by the bioethics committee at the regional medical chamber in Krakow, Poland (Approval No. 115/ KBL/OIL/2012).

\section{Conflict of interest}

The authors declare no conflict of interest.

\section{References}

1. Murray CJ, Vos T, Lozano R, et al. Disability-adjusted life years (DALYs) for 291 diseases and injuries in 21 regions, 1990-2010: a systematic analysis for the Global Burden of Disease Study 2010. Lancet 2012; 380: 2197-223.

2. Moran AE, Forouzanfar MH, Roth GA, et al. The global burden of ischemic heart disease in 1990 and 2010: the Global Burden of Disease 2010 study. Circulation 2014; 129: 1493-501.

3. Park KE, Conti CR. Non-PCI/CABG therapies for refractory angina. Trends Cardiovasc Med 2018; 28: 223-8.

4. Morrison DA, Sethi G, Sacks J, et al. Percutaneous coronary intervention versus coronary artery bypass graft surgery for patients with medically refractory myocardial ischemia and risk factors for adverse outcomes with bypass: a multicenter, randomized trial. Investigators of the Department of Veterans Affairs Cooperative Study \#385, the Angina With Extremely Serious Operative Mortality Evaluation (AWESOME). J Am Coll Cardiol 2001; 38: 143-9.

5. Povsic TJ. Current state of stem cell therapy for ischemic heart disease. Curr Cardiol Rep 2016; 18: 17.

6. Povsic TJ, Broderick S, Anstrom KJ, et al. Predictors of long-term clinical endpoints in patients with refractory angina. J Am Heart Assoc 2015; 4: pii: e001287.

7. Picichè M. Old methods of myocardial revascularization to treat refractory angina. J Cardiovasc Med (Hagerstown) 2018; 19: 261.

8. Fisher SA, Dorée C, Brunskill SJ, et al. Bone marrow stem cell treatment for ischemic heart disease in patients with no option of revascularization: a systematic review and meta-analysis. PLoS One 2013; 2013: e64669.

9. Li N, Yang YJ, Zhang Q, et al. Stem cell therapy is a promising tool for refractory angina: a meta-analysis of randomized controlled trials. Can J Cardiol 2013; 29: 908-14.

10. Tavris DR, Brennan JM, Sedrakyan A, et al. Long-term outcomes after transmyocardial revascularization. Ann Thorac Surg 2012; 94: $1500-8$ 
11. Briones E, Lacalle JR, Marin I. Transmyocardial laser revascularization versus medical therapy for refractory angina. Cochrane Database Syst Rev 2009; 2: CD003712.

12. Kindzelski BA, Zhou Y, Horvath KA, Transmyocardial revascularization devices: technology update. Med Devices 2015; 8: 11-9.

13. Singh A, Singh A, Sen D. Mesenchymal stem cells in cardiac regeneration: a detailed progress report of the last 6 years (20102015). Stem Cell Res Ther 2016; 71: 82.

14. Stoltz JF, de Isla N, Li YP, et al. Stem cells and regenerative medicine: myth or reality of the 21th century. Stem Cells Int 2015; 2015: 734731.

15. Koobatian MT, Liang MS, Swartz DD, et al. Differential effects of culture senescence and mechanical stimulation on the proliferation and leiomyogenic differentiation of MSC from different sources: implications for engineering vascular grafts. Tissue Eng Part A 2015; 21: 1364-75.

16. Zuk PA, Zhu M, Ashjian P, et al. Human adipose tissue is a source of multipotent stem cells. Mol Biol Cell 2002; 13: 4279-95.

17. Cai L, Johnstone BH, Cook TG, et al. IFATS Collection: human adipose tissue-derived stem cells induce angiogenesis and nerve sprouting following myocardial infarction, in conjunction with potent preservation of cardiac function. Stem Cells 2009; 27: 230-7.

18. Badimon L, Oñate B, Vilahur G. Adipose-derived mesenchymal stem cells and their reparative potential in ischemic heart disease. Rev Esp Cardiol 2015; 68: 599-611.

19. Rehman J, Traktuev D, Li J, et al. Secretion of angiogenic and antiapoptotic factors by human adipose stromal cells. Circulation 2004; 109: 1292-8.

20. Stubbs SL, Hsiao STF, Peshavariya HM, et al. Hypoxic preconditioning enhances survival of human adipose-derived stem cells and conditions endothelial cells in vitro. Stem Cells Dev 2012; 21: 1887-96.

21. Frese L, Dijkman PE, Hoerstrup SP. Adipose tissue-derived stem cells in regenerative medicine. Transfus Med Hemother 2016; 43: 268-74.

22. Suzuki E, Fujita D, Takahashi M, et al. Adipose tissue-derived stem cells as a therapeutic tool for cardiovascular disease. World J Cardiol 2015; 7: 454-65.

23. Henry TD, Pepine CJ, Lambert CR, et al. The Athena trials: autologous adipose-derived regenerative cells for refractory chronic myocardial ischemia with left ventricular dysfunction. Catheter Cardiovasc Interv 2017; 89: 169-77.

24. Patel AN, Spadaccio C, Kuzman M, et al. Improved cell survival in infarcted myocardium using a novel combination transmyocardial laser and cell delivery system. Cell Transplant 2007; 16 : 899-905

25. Spiegelstein D, Kim C, Zhang Y, et al. Combined transmyocardial revascularization and cell-based angiogenic gene therapy increases transplanted cell survival. Am J Physiol Heart Circ Physiol 2007; 293: H3311-6.

26. Konstanty-Kalandyk J, Piątek J, Miszalski-Jamka T, et al. The combined use of transmyocardial laser revascularisation and intramyocardial injection of bone-marrow derived stem cells in patients with end-stage coronary artery disease: one year follow-up. Kardiol Pol 2013; 71: 485-92.

27. Schaun MI, Eibel B, Kristocheck M, et al. Cell therapy in ischemic heart disease: interventions that modulate cardiac regeneration. Stem Cells Int 2016; 2016: 2171035.

28. Fraser JK, Hicok KC, Shanahan R, et al. The celution system: automated processing of adipose-derived regenerative cells in a functionally closed system. Adv Wound Care (New Rochelle) 2014; 3: 38-45.

29. Houtgraaf JH, den Dekker WK, van Dalen BM, et al. Duckers, first experience in humans using adipose tissue-derived regenerative cells in the treatment of patients with ST-segment elevation myocardial infarction. J Am Coll Cardiol 2012; 59: 539-40.

30. Perin EC, Sanz-Ruiz R, Sánchez PL, et al. Adipose-derived regenerative cells in patients with ischemic cardiomyopathy: the PRECISE Trial. Am Heart J 2014; 168: 88-95.e2.

31. Qayyum AA, Haack-Sørensen M, Mathiasen AB, et al. Adipose-derived mesenchymal stromal cells for chronic myocardial ischemia (MyStromalCell Trial): study design. Regen Med 2012; 7: 421-8.

32. Andréll P, Ekre O, Grip L, et al. Fatality, morbidity and quality of life in patients with refractory angina pectoris. Int J Cardiol 2011; 147: 377-82.

33. Khan AR, Farid TA, Pathan A, et al. Impact of cell therapy on myocardial perfusion and cardiovascular outcomes in patients with angina refractory to medical therapy: a systematic review and meta-analysis. Circ Res 2016; 118: 984-93.

34. Watanabe CT, Lee S, Daniels E, et al. Others, intracoronary adipose tissue-derived stem cell therapy preserves left ventricular function in a porcine infarct model. Am J Cardiol 2004; 94 (Suppl. 1): $188 \mathrm{E}$.

35. Yin QX, Wang H, Pei ZY, et al. Efficacy of cyclosporine A-nanoparticles emulsion combined with stem cell transplantation therapy for acute myocardial infarction. Zhongguo Yi Xue Ke Xue Yuan Xue Bao 2013; 35: 404-10.

36. Musialek P, Tekieli L, Kostkiewicz M, et al. Randomized transcoronary delivery of CD34+ cells with perfusion versus stop-flow method in patients with recent myocardial infarction: early cardiac retention of $99 \mathrm{mTc}$-labeled cells activity. J Nucl Cardiol 2011; 18: 104-16.

37. Pavo N, Charwat S, Nyolczas N, et al. Cell therapy for human ischemic heart diseases: critical review and summary of the clinical experiences. J Mol Cell Cardiol 2014; 75: 12-24.

38. Donndorf P, Kundt G, Kaminski A, et al. Intramyocardial bone marrow stem cell transplantation during coronary artery bypass surgery: a meta-analysis. J Thorac Cardiovasc Surg 2011; 142: 911-20.

39. Beeres SLMA, Bax JJ, Dibbets P, et al. Effect of intramyocardial injection of autologous bone marrow-derived mononuclear cells on perfusion, function, and viability in patients with drug-refractory chronic ischemia. J Nucl Med 2006; 47: 574-80. 